\title{
Aqueous Geochemistry and Limnology of the Sleeper Pit Lake, Nevada, USA: Evidence for Long-Term Subaqueous Solute Generation in Mine Pit Lakes
}

\author{
Connor P. Newman ${ }^{*}{ }^{\oplus}$, Tyler Cluff ${ }^{2}$, Thomas Gray ${ }^{1}$, Geoff Beale $^{3}$ \\ ${ }^{1}$ Nevada Division of Environmental Protection, Carson City, NV, USA \\ ${ }^{2}$ Piteau Associates, Reno, NV, USA \\ ${ }^{3}$ Piteau Associates, Shrewsbury, UK \\ Email: *connor.newman1988@gmail.com
}

How to cite this paper: Newman, C. P., Cluff, T., Gray, T., \& Beale, G. (2019). Aqueous Geochemistry and Limnology of the Sleeper Pit Lake, Nevada, USA: Evidence for Long-Term Subaqueous Solute Generation in Mine Pit Lakes. Journal of Geoscience and Environment Protection, 7, 64-81.

https://doi.org/10.4236/gep.2019.73004

Received: December 17, 2018

Accepted: March 11, 2019

Published: March 14, 2019

Copyright $\odot 2019$ by author(s) and Scientific Research Publishing Inc. This work is licensed under the Creative Commons Attribution International License (CC BY 4.0).

http://creativecommons.org/licenses/by/4.0/

\begin{abstract}
Predictive geochemical and limnologic modeling of pit lakes is an important aspect of modern mine-site permitting. One of the key assumptions of many predictive pit-lake models is that open-pit high walls and in-pit backfill become geochemically unreactive once submerged by the filling pit lake. Existing pit lakes provide useful data to test this assumption. The Sleeper pit lake (northwestern Nevada, USA) is approaching hydrologic equilibrium and contains good-quality water that generally meets regulatory requirements for pit lakes. Despite the overall stable geochemical composition, seasonal trends in the hypolimnion indicate the generation of dissolved metals associated with the ore deposit (e.g., $\mathrm{Mn}$ and $\mathrm{Zn}$ ) and cyclical variations in $\mathrm{pH}$. This study applies mass balance, analysis of subaqueous pyrite oxidation, and trends in solute concentrations to evaluate the potential causes of long-term solute generation in the hypolimnion of the Sleeper pit lake. Three separate conceptual models (subaqueous pyrite oxidation; redox reactions; and diffusion of solutes from a permanently stratified bottom layer) were tested against the high-quality dataset available for the pit lake. Evaluation of the monitoring dataset for the pit lake indicates that the Sleeper pit lake has variable limnologic behavior, wherein the lake is consistently stratified (meromictic) in some years, while it undergoes full mixing (holomixis) in other time periods. Comparison of the data with the three conceptual models illustrates that none of these models can be completely implicated as causing the seasonal geochemical variations in the bottom of the pit lake, but that a combination of the processes is likely partially responsible. Additional data collec-
\end{abstract}


tion including sediment cores and in-situ pore-water analysis would aid in understanding geochemical processes occurring over time.

\section{Keywords}

Mine Pit Lakes, Limnology, Subaqueous Sulfide Oxidation, Redox Reactions, Meromixis

\section{Introduction}

Modern mining operations are becoming more reliant on open-pit mining methods to economically produce ore deposits of lower grade. Depending on the relationship of these open pits to the local groundwater table, active dewatering operations are in some instances required to allow mining to commence. When dewatering is discontinued at the conclusion of mining, groundwater and surface water fill the open pit, creating a mine pit lake (Castendyk \& Eary, 2009). Pit lakes are becoming a prominent issue around the world (Kumar et al., 2009; Ramteke et al., 2016; Sánchez-España et al., 2008), and have resulted in substantial environmental contamination and been the subject of advanced remediation measures (Tucci \& Gammons, 2015).

As mine pit lakes become more widespread, regulatory agencies are increasingly requiring advanced predictive modeling of pit-lake geochemistry during mine permitting. The end goal of all those involved in these permitting actions (i.e., the mining company, the regulatory agencies, and the public) is to have pit lakes become geochemically and hydrologically stable for the long term, which may then allow mining permits to be relinquished. Modeling endeavors therefore are important to inform long-term closure of pit lakes. The conceptual models and numerical methods used to predict pit-lake water quality are complex and require substantial amounts of data and a variety of assumptions (Castendyk et al., 2015). One of the common modeling assumptions is that solute generation via acid mine drainage is eliminated (or at least decreased) by the filling of the pit lake and inundation of high walls and any in-pit waste rock. However, few studies have reported on observations that support or refute this assumption. The water-quality records of existing pit lakes provide ideal datasets to test these assumptions.

Pit lakes commonly are somewhat unique limnologically, due to the different surface area to depth ratio (termed the relative depth) when compared to natural lakes (Castendyk, 2009). Hydrodynamic and geochemical conditions in pit lakes may lead to pronounced vertical stratification, wherein several geochemically distinct layers form that may not mix with one another. These layers may include the epilimnion (upper-most layer), metalimnion (transition layer), hypolimnion (lower-most layer that participates in mixing), and monimolimnion (semi-permanently stratified bottom layer). If the separate layers of a pit lake 
experience full mixing at least once annually that pit lake is termed holomictic, whereas a pit lake with a monimolimnion (which rarely or never fully mixes with the rest of the pit lake) is termed meromictic. There are various ways in which the limnologic behavior of pit lakes can be predictively evaluated (Jewell, 2009), although these are not always effective in predicting the limnology observed in pit lakes (Schultze \& Boehrer, 2009). The difference between meromictic and holomictic pit lakes may be important from a regulatory perspective because different modeling and management assumptions are applicable to the different limnologic behaviors (Schultze et al., 2016).

\section{Study Site}

The former Sleeper mine is located in northwestern Nevada (Figure 1), and has

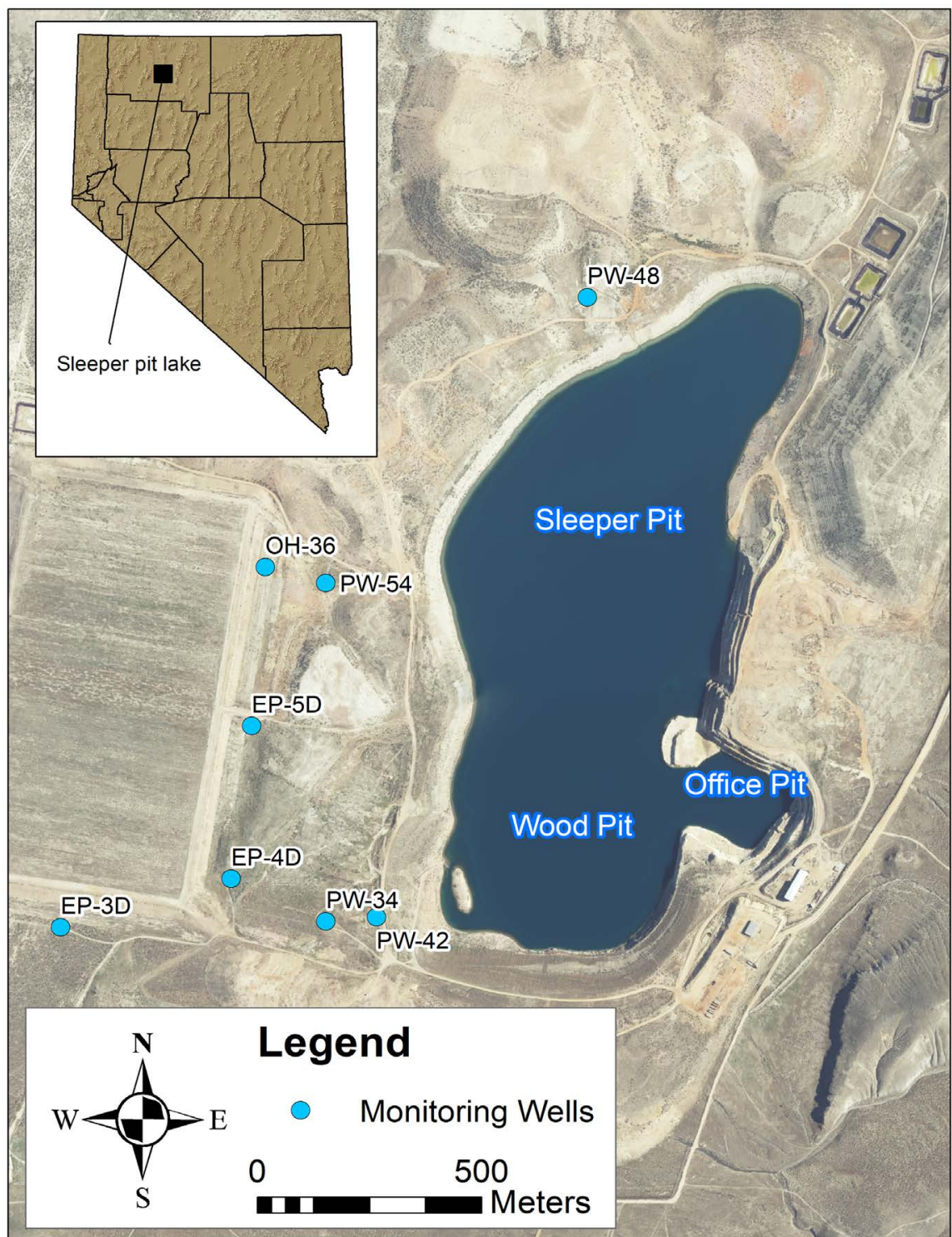

Figure 1. Regional location of the sleeper pit lake and on-site groundwater monitoring wells. 
been inactive (in terms of ore extraction) since 1996. The mine extracted Au and Ag from the famous high-grade Sleeper vein and associated widespread stockwork mineralization (Nash et al., 1995). Water quality in the pit lake has been monitored since the cessation of dewatering in 1996. The current pit lake actually occupies three separate sub-pits, the Sleeper, Wood, and Office pits (Figure 1). The Sleeper and Wood pits undergo regular water-column monitoring using a conductivity-temperature-depth (CTD) probe, and sampling for dissolved inorganic constituents at several depths $(3,40$, and $100 \mathrm{~m}[\sim 10, \sim 130$, and $\sim 330 \mathrm{ft}$. respectively] below lake surface). Groundwater quality in the vicinity of the pit lake is also monitored using a series of wells (Figure 1).

During the initial closure of the Sleeper mine a novel technique at the time was utilized wherein nearby groundwater was pumped into the open pit to minimize the period of exposure of acid generating high walls near the bottom of the pit and waste rock that was backfilled into the pit (Dowling et al., 2004). This rapid-fill approach resulted in the pit lake nearing its final predicted stage elevation much more quickly than would have occurred under normal hydrogeologic conditions. The rapid-fill also included episodic lime dosing. Prior to the rapid fill, the pits were partially backfilled to cover unoxidized portions of the pit floors and walls with both oxidized and unoxidized waste rock, which was amended with lime in some instances. During initial infilling, the pit lake contained moderately acidic water with elevated concentrations of dissolved metals and metalloids such as $\mathrm{As}, \mathrm{Cd}, \mathrm{Cu}$, and $\mathrm{Mn}$. However, supplemental lime addition resulted in the pit lake rapidly (within approximately three years) attaining a circumneutral $\mathrm{pH}$ with a dramatic decrease in concentrations of the aforementioned constituents. The implemented closure strategy is likely responsible for the rapid and long-term stabilization of the pit-lake water quality.

Although the current pit lake overall has a relatively stable and good-quality water chemistry, seasonal changes are evident in the hypolimnion (assumed to be represented by water quality in the sample from $100 \mathrm{~m}$ [330 ft.] depth). These changes constitute fluctuations of $\mathrm{pH}$, alkalinity and the dissolved concentrations of metals such as $\mathrm{Zn}$ and $\mathrm{Mn}$. At present, these trends do not cause major changes in the closure plan or regulatory compliance, but they may be indicative of important geochemical processes occurring in the lake with possible future implications at the Sleeper mine and other pit lakes. The purpose of this paper is to explore three potential conceptual models that may cause these seasonal changes:

A) Pyrite oxidation may be ongoing in the submerged backfill leading to fluxes of associated constituents ( $\mathrm{Zn}, \mathrm{Fe}$, etc.) in the hypolimnion. These constituents may then be diluted by the less concentrated shallower waters of the epilimnion during turnover events;

B) Redox processes may cause benthic fluxes to contribute dissolved metals seasonally to the hypolimnion waters; or,

C) The pit lake may have a permanently stratified bottom layer (monimolim- 
nion), with elevated metal concentrations, that has never been sampled. During the stratified time period diffusion of dissolved solutes in the monimolimnion to the hypolimnion causes observed water quality changes, while these changes are masked by dilution during mixing events between the epilimnion and hypolimnion.

Potential methods by which these end-member scenarios (or combinations thereof) may be assessed are detailed in the following section.

\section{Methods and Data}

Water-quality samples have been collected from various depths within the Sleeper pit lake for approximately the past 22 years. As such a very complete dataset exists consisting of quarterly compliance samples and CTD probe measurements collected on variable frequencies. Water-quality samples from the pit lake at depth are collected using a Kemmerer sampling bottle. Surface samples are not filtered, while depth samples are filtered to $0.45 \mu \mathrm{m}$. Samples for analysis of anion concentrations were refrigerated and analysis was carried out using ion chromatography. Samples for analysis of dissolved metals were acidified following filtration (for depth samples) and were refrigerated. Metal concentrations were quantified using U.S. Environmental Protection Agency (EPA) method 200.2. All aqueous geochemical results were evaluated for charge balance. Although surface samples are unfiltered, no systematic differences in metal content has been noted between surface samples and metalimnion samples (collected from approximately $40 \mathrm{~m}$ [130 ft.] below lake surface). As such it appears that the majority of metals in the pit lake are present in dissolved form. This study utilized all water-quality monitoring data and CTD data to evaluate the aforementioned conceptual models.

As described by Gammons (2009), oxidation of pyrite ( $\mathrm{FeS}_{2}$; the most common sulfide mineral in many ore deposits) can proceed with either oxygen $\left(\mathrm{O}_{2}\right)$ or ferric $\mathrm{Fe}\left(\mathrm{Fe}^{\mathrm{IIII}}\right)$ as the oxidant. The rate of oxidation by these two species can be calculated according to Equation (1) (for $\mathrm{O}_{2}$ ) and Equation (2) (for $\mathrm{Fe}^{\mathrm{III}}$ ):

$$
\begin{gathered}
r_{\mathrm{O}_{2}}=10^{-8.1} \frac{\left[\mathrm{O}_{2}\right]^{0.5}}{\left[\mathrm{H}^{+}\right]^{0.11}} \\
r_{\mathrm{Fe}}=10^{-6.71} \times \mathrm{Eh}^{7.96} \times \mathrm{pH}^{1.06}
\end{gathered}
$$

where $r$ represents the oxidation rate $\left(\mathrm{mol} / \mathrm{m}^{2} \cdot \mathrm{sec}\right)$, square brackets represent the molal concentration of the given species, and Eh represents the oxidation-reduction potential $(\mathrm{V})$ corrected to the standard hydrogen electrode. Although both $\mathrm{pH}$ and Eh are recorded by the CTD, the availability of CTD data is sporadic and Eh measurements are not available for the entire filling history. Therefore, recent Eh measurements (from August 2018) were utilized in all calculations for the rate of oxidation by $\mathrm{Fe}^{\mathrm{III}}$. This has the net effect of increasing uncertainty as to how this process impacts water quality. Also, Equation (2) is only applicable if the water is in equilibrium with respect to ferrihydrite (Gam- 
mons, 2009). This requirement is met in the majority, but not all, of the sampling events utilized in these calculations. Of the 63 representative hypolimnion concentrations utilized in this analysis 58 displayed ferrihydrite saturation index (SI) values greater than 0 (indicating propensity for precipitation). In support of these calculations, the total acidity of the pit lake was also calculated using the methodology of Kirby and Cravotta (2005) shown in Equation (3), which allows assessment of the total acidity load in the pit lake to be quantified in addition to the observed $\mathrm{pH}$ changes (which only quantifies hydrogen acidity).

$$
A=50\left\{\left(1000 \times 10^{-\mathrm{pH}}\right)+\left(\frac{2 \times[\mathrm{Mn}]}{55}\right)+\left(\frac{3 \times\left[\mathrm{Fe}_{\text {Total }}\right]}{56}\right)+\left(\frac{3 \times[\mathrm{Al}]}{27}\right)\right\}
$$

where $A$ denotes acidity $\left(\mathrm{mg} / \mathrm{L}\right.$ as $\left.\mathrm{CaCO}_{3}\right), \mathrm{pH}$ is in standard units, and $[\mathrm{Mn}]$, $[\mathrm{Fe}]$, and [Al] respectively denote the concentration of $\mathrm{Mn}, \mathrm{Fe}$, and $\mathrm{Al}$ (all $\mathrm{mg} / \mathrm{L}$ ). Kirby and Cravotta (2005) differentiate between the acidity of ferrous $\mathrm{Fe}$ $\left(\mathrm{Fe}^{\mathrm{II}}\right)$ and ferric $\mathrm{Fe}\left(\mathrm{Fe}^{\mathrm{III}}\right)$, which may be important in some systems. No Fe speciation analytical results are available for the Sleeper pit lake however. As such all Fe was considered as ferric in the calculations, which would tend to overestimate metal acidity from $\mathrm{Fe}$. As detailed below in the results section, Fe is not the most abundant metal throughout the majority of the monitoring record. Therefore the effect of assuming ferric versus ferrous Fe is likely not consequential to the results.

To evaluate conceptual model B (that redox reactions and benthic fluxes impact the lake chemistry), the depth profiles of various constituents were compared with one another over time, and simple redox reactions were considered. It is important to note however that benthic fluxes cannot be quantitatively evaluated without the use of in-situ measurements (e.g., using diffusion-controlled dialysis samplers, a.k.a. peepers; Martin \& Pedersen, 2002). The analysis presented herein is therefore conceptual only. Eary and Castendyk (2013) summarize a variety of potential sediment biogeochemical processes that may occur in pit lakes, specifically with respect to the oxidation of organic carbon and pyrite, and the reduction of metal oxyhydroxides according to reactions shown in Equations (4)-(8), where $\mathrm{C}_{\text {org }}$ represents organic carbon (simplified for this analysis), and solids are denoted using the subscript (s). Overall, these series of reactions can be combined (including multiplication to balance species) into the net Reaction (9).

$$
\begin{gathered}
\mathrm{MnO}_{2(\mathrm{~s})}+2 \mathrm{e}^{-}+4 \mathrm{H}^{+} \leftrightarrow \mathrm{Mn}^{2+}+2 \mathrm{H}_{2} \mathrm{O} \\
\mathrm{FeS}_{2(\mathrm{~s})}+\frac{7}{2} \mathrm{O}_{2}+\mathrm{H}_{2} \mathrm{O} \leftrightarrow \mathrm{Fe}^{2+}+2 \mathrm{SO}_{4}^{2-}+2 \mathrm{H}^{+} \\
\mathrm{C}_{\text {org }}+2 \mathrm{H}_{2} \mathrm{O} \leftrightarrow \mathrm{CO}_{2}+4 \mathrm{H}^{+}+4 \mathrm{e}^{-} \\
\mathrm{Fe}^{2+}+\frac{1}{4} \mathrm{O}_{2}+\mathrm{H}^{+} \leftrightarrow \mathrm{Fe}^{3+}+\frac{1}{2} \mathrm{H}_{2} \mathrm{O} \\
\mathrm{Fe}^{3+}+3 \mathrm{H}_{2} \mathrm{O} \leftrightarrow \mathrm{Fe}(\mathrm{OH})_{3(\mathrm{~s})}+3 \mathrm{H}^{+}
\end{gathered}
$$




$$
\begin{aligned}
& \mathrm{MnO}_{2(\mathrm{~s})}+4 \mathrm{FeS}_{2(\mathrm{~s})}+\mathrm{C}_{\mathrm{org}}+14 \mathrm{H}_{2} \mathrm{O}+15 \mathrm{O}_{2} \\
& \leftrightarrow \mathrm{Mn}^{2+}+8 \mathrm{SO}_{4}^{2-}+\mathrm{CO}_{2}+4 \mathrm{Fe}(\mathrm{OH})_{3(\mathrm{~s})}+16 \mathrm{H}^{+}+2 \mathrm{e}^{-}
\end{aligned}
$$

This reaction conceptually represents the oxidation of pyrite with dissolved oxygen to form an Fe-oxyhydroxide (ferrihydrite is commonly assumed in these conditions), combined with the reduction of Mn-oxide (which could be pyrolusite or another phase) with organic carbon as an electron donor. This reaction is conceptual only, as no observations of such phase transformations are available for the Sleeper pit lake. Several aspects of the net reaction are noteworthy. First, the reaction as written requires four moles of pyrite for every mole of organic matter and Mn-oxide. Second, the reaction produces substantial amounts of sulfate ( 8 moles) and acidity (16 moles of hydrogen ions). Also, it could be relevant to discuss the reduction of Fe-oxyhydroxides (such as ferrihydrite), but reduction of these minerals occurs at lesser Eh values (more reducing conditions) than for Mn-oxyhydroxides (Appelo \& Posta, 2005). Therefore reductive dissolution of Fe-oxyhydroxides was not considered in this analysis, although future evaluation of this process may be appropriate.

Although these phase transformations have not been investigated in the Sleeper pit lake using sediment sampling or analysis of pore waters, the plausibility of the overall reaction can be evaluated by quantifying the changes in Mn concentration in relation to sulfate and $\mathrm{pH}$, precisely because of the stoichiometry discussed above. Additionally, this reaction is consistent with the oxidation of pyrite while maintaining low dissolved Fe concentrations, as is observed in the pit lake and discussed below in the results section.

Finally, to evaluate conceptual model C (diffusion of water from a thin monimolimnion of unknown composition or from sediment pore-waters), an analytical form of Fick's law of diffusion may be used according to:

$$
q_{z}=-D \frac{\mathrm{d} C}{\mathrm{~d} z}
$$

where $q_{z}$ represents diffusive flux in the $z$ dimension $\left(\mathrm{mol} / \mathrm{m}^{2} \cdot \mathrm{sec}\right), D$ represents the diffusion coefficient for the given species $\left(\mathrm{m}^{2} / \mathrm{sec}\right)$, and $\mathrm{d} C / \mathrm{d} z$ represents the concentration gradient in the $z$ dimension $(\mathrm{mol} / \mathrm{m})$. To calculate the total mass of diffusive transport, the area over which diffusion acts must be known. For this analysis this area was calculated as the approximate area of the bottom of the pit lake, where diffusion from the saturated sediments or the monimolimnion would conceptually take place. Diffusion coefficients (D) vary between sources. For this analysis the online reference Aqion (2018) was utilized.

\section{Results and Discussion}

\subsection{Seasonal Geochemical Fluctuations and Limnologic Behavior}

The Sleeper pit lake is circumneutral. Seasonal fluxes of various constituents are observed by plotting the water quality of the hypolimnion and epilimnion waters through time (Figure 2). These seasonal changes include decreasing alkalinity 


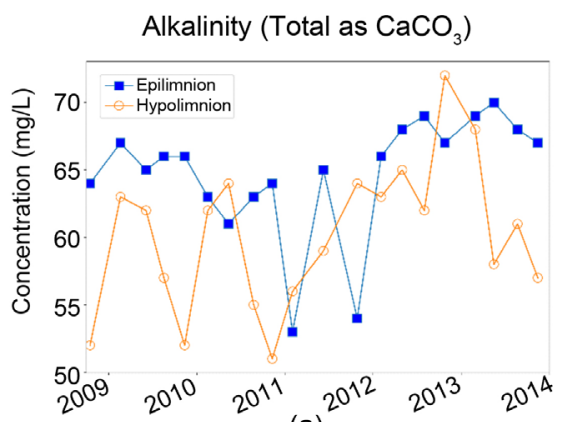

(a)

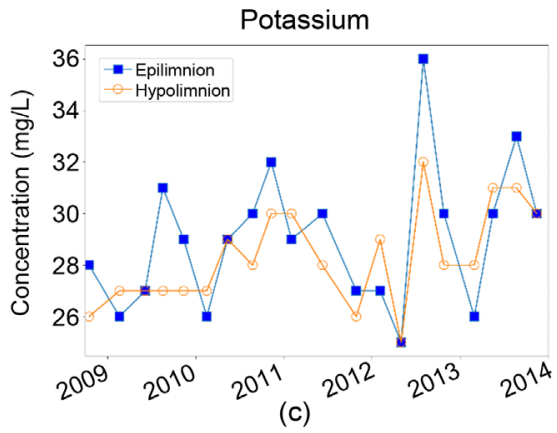

Manganese

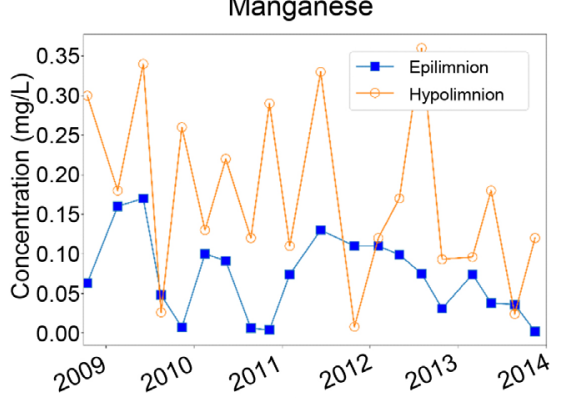

(e)

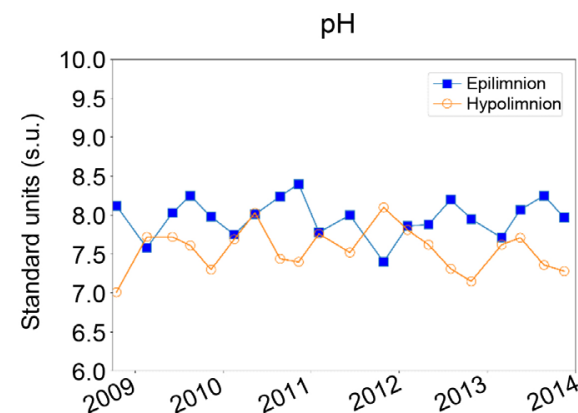

(b)
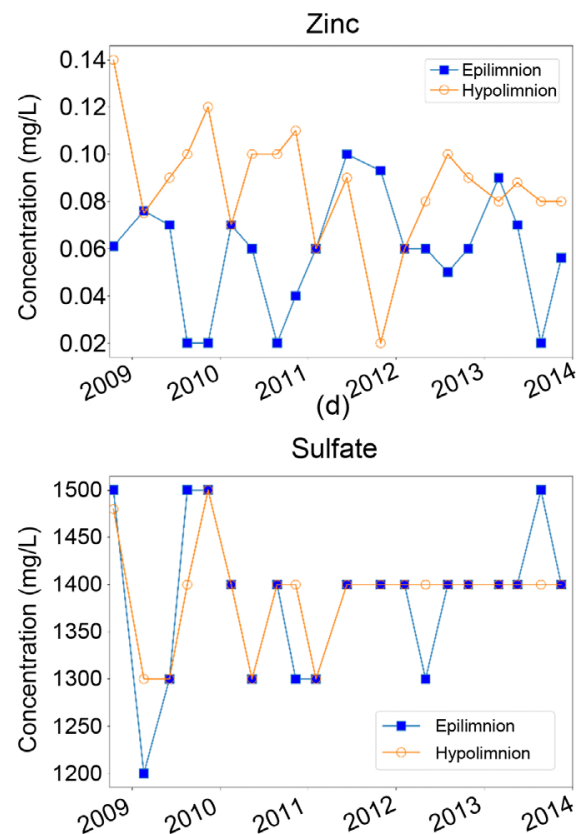

(f)

Figure 2. Seasonal fluctuations during the period 2009-2014 of: (a) total alkalinity, (b) $\mathrm{pH}$, (c) K, (d) $\mathrm{Zn},(\mathrm{e}) \mathrm{Mn}$, and (f) sulfate.

(Figure 2(a)) and $\mathrm{pH}$ (Figure 2(b)) in the hypolimnion during the summer season when lake stratification is strongest. In combination with this stratification, $\mathrm{K}$ (which is generally conservative) shows an increasing trend in the epilimnion during the summer (Figure 2(c)), possibly reflecting evapoconcentration. During the period in which the epilimnion is concentrating $\mathrm{K}$, the hypolimnion waters show increasing Zn (Figure 2(d)) and Mn (Figure 2(e)) concentrations. During the turnover event each year the concentrations of most dissolved solutes and the $\mathrm{pH}$ of the lake generally homogenize with depth. An exception to this trend is during late 2011 when the hypolimnion and epilimnion remained decoupled in their geochemical characteristics, potentially indicating that the pit lake did not turn over in this period. The sulfate concentrations in the pit lake do not change appreciably on a seasonal basis (Figure 2(f)).

Seasonal changes in water quality may also be evaluated with respect to the total acidity of the lake (i.e., metal acidity plus hydrogen acidity). Figure 3 illustrates the changes in acidity in both the epilimnion and hypolimnion over time. 


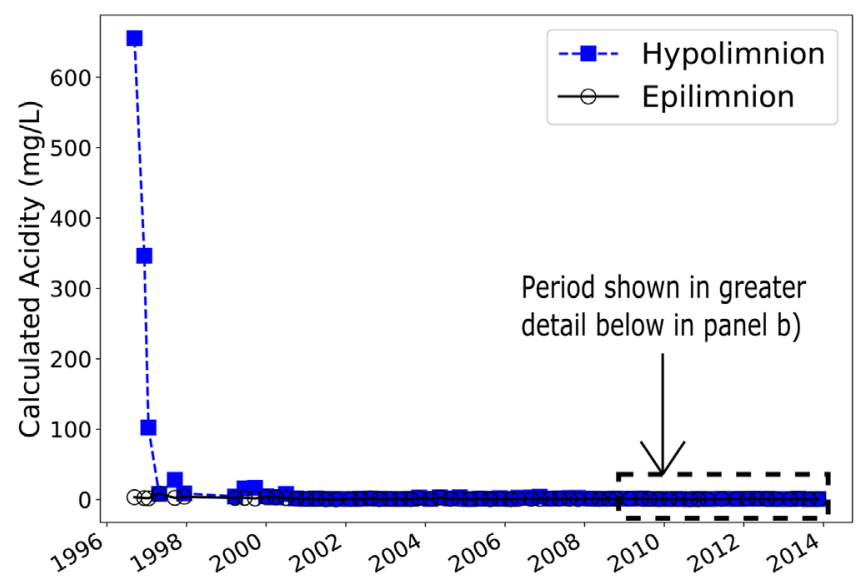

(a)

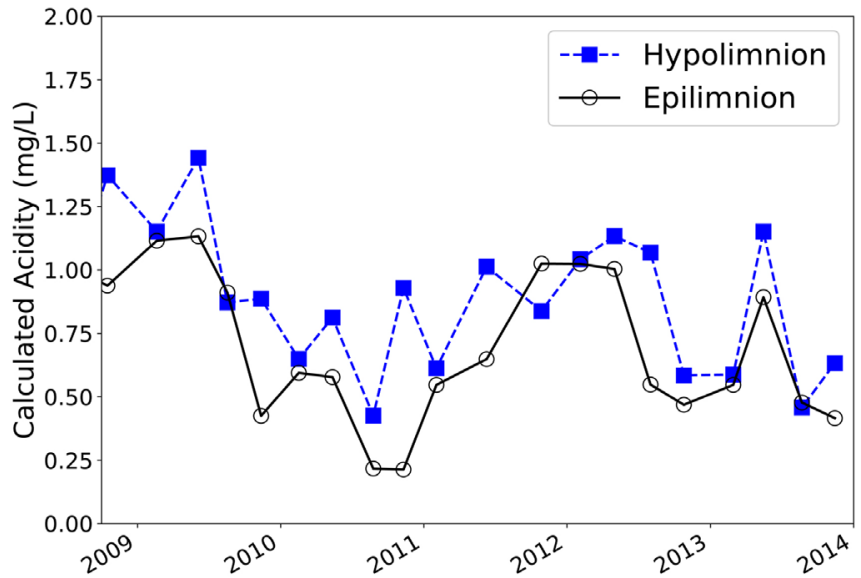

(b)

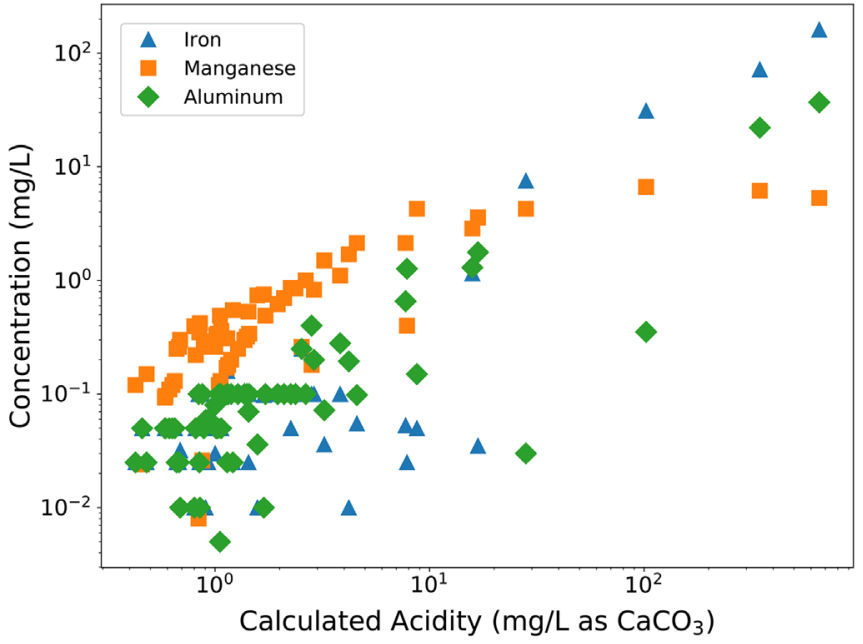

(c)

Figure 3. Changes in calculated acidity over (a) the period of record for the pit lake, (b) the selected detail period of 2009-2014, and (c) correlations of calculated acidity with $\mathrm{Al}, \mathrm{Fe}$, and $\mathrm{Mn}$.

Figure 3(a) illustrates that upon initial filling the hypolimnion had substantial acidity ( $>600 \mathrm{mg} / \mathrm{L}$ as $\mathrm{CaCO}_{3}$ ) and elevated dissolved $\mathrm{Fe}, \mathrm{Al}$, and $\mathrm{Mn}$ concentra- 
tions (Figure $3(\mathrm{c})$ ). This acidity was rapidly neutralized and the epilimnion had little initial acidity. The elevated dissolved metal concentrations in the hypolimnion were likely due to flushing of the in-pit waste rock and enhanced oxidation during initial filling. Illustrated in Figure 3(b) are seasonal fluctuations in calculated acidity in more recent years. These reflect the changing $\mathrm{pH}$ of the water column during the summer (Figure 2(b)) as well as seasonal loading of Mn. Seasonal patterns are clearer in the hypolimnion, although some long-term and seasonal changes are also observed for the epilimnion. It should be noted that the seasonal changes observed in Figure 3(b) are visually distinct but quantitatively minor, with acidity loading of only approximately $0.5 \mathrm{mg} / \mathrm{L}$ as $\mathrm{CaCO}_{3}$ during the summer months. The correlations shown in Figure 3(c) indicate that initially the majority of metals acidity was related to elevated Fe concentrations. At lesser calculated acidity concentrations however (generally representing year 2000 and later) Figure 3(c) shows that Mn makes up the majority of metals acidity.

Although it is commonly assumed in pit-lake predictive studies that all pit lakes in Nevada are holomictic (i.e., they experience full turnover of the water column at least once per year), and the Sleeper pit lake has been observed to turnover annually in the past (Dowling et al., 2004), current observations illustrate that the pit lake is meromictic in some years (i.e., it remains stratified for periods of greater than one year). If a given Nevada pit lake does experience full mixing, this process commonly occurs during either the fall and/or spring seasons when wind stress is at a maximum and thermal inversion serves to destabilize the existing stratification (Balistrieri et al., 2006).

The limnologic behavior of the Sleeper pit lake over various timescales is illustrated in Figure 4. While Figure 2 indicates clearly that the pit lake has been largely holomictic in recent years, Figure 4 illustrates a time period in which the lake apparently remained stratified for longer than a year. Beginning with Figure 4(a) in fall of 2005, the pit lake was clearly stratified in both the Sleeper and Wood pits with respect to dissolved oxygen (DO) and $\mathrm{pH}$. The pit lake retained this stratification through the winter of 2005/2006 (Figure 4(b) and Figure $4(\mathrm{c})$ ), through the following spring (Figure $4(\mathrm{~d})$ ), and potentially through summer 2006 (Figure 4(e)). There is some uncertainty however as to the limnologic behavior in late summer of 2006. Concentrations of DO indicate that the pit lake may have experienced turnover at some point between May 2006 (Figure 4(d)) and August 2006 (Figure 4(e)), given that DO concentrations are not substantially changed between the two sampling events. It is possible that turnover occurred shortly after May 2006, and stratification is being established again by August 2006. Monthly water-column profiling (e.g., von Rohden et al., 2010) would be better suited to long-term limnologic analyses to evaluate turnover frequency. The exact cause of the variable limnologic behavior is not known, but stratification could be maintained by relatively dilute water that flows into the upper portion of the pit lake from the basal alluvial gravel aquifer, 


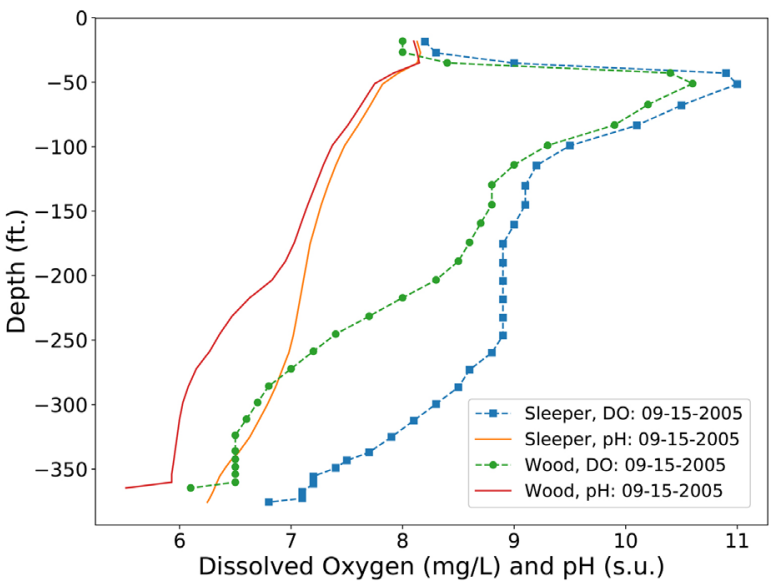

(a)

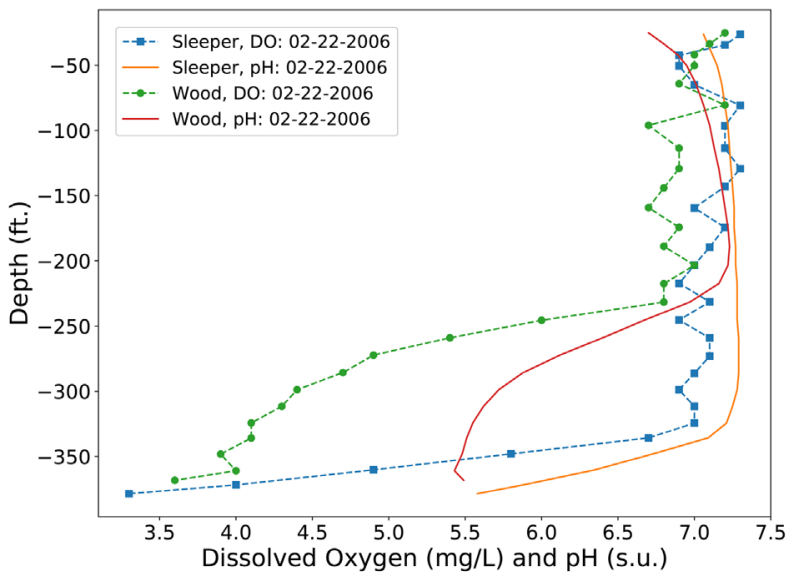

(c)

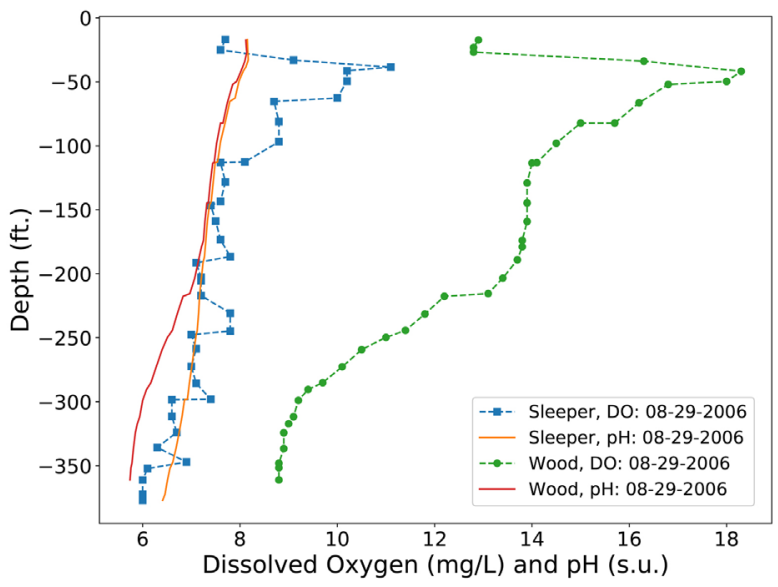

(e)

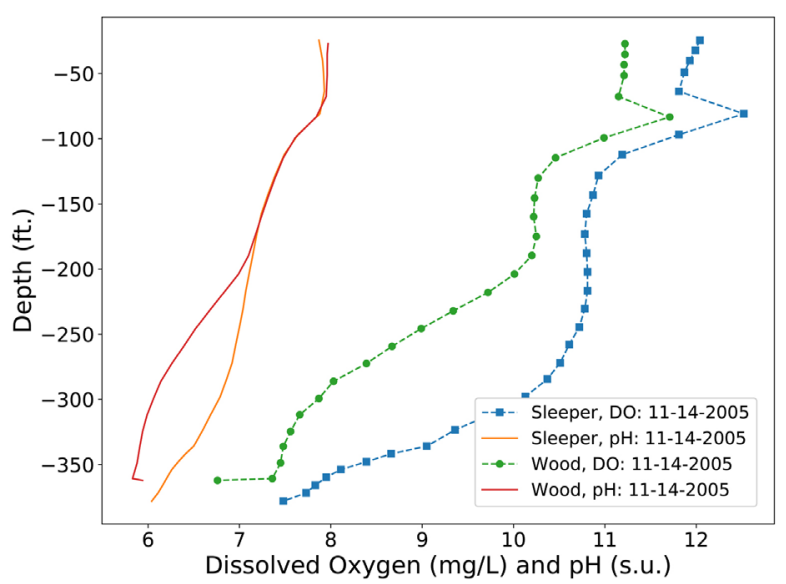

(b)

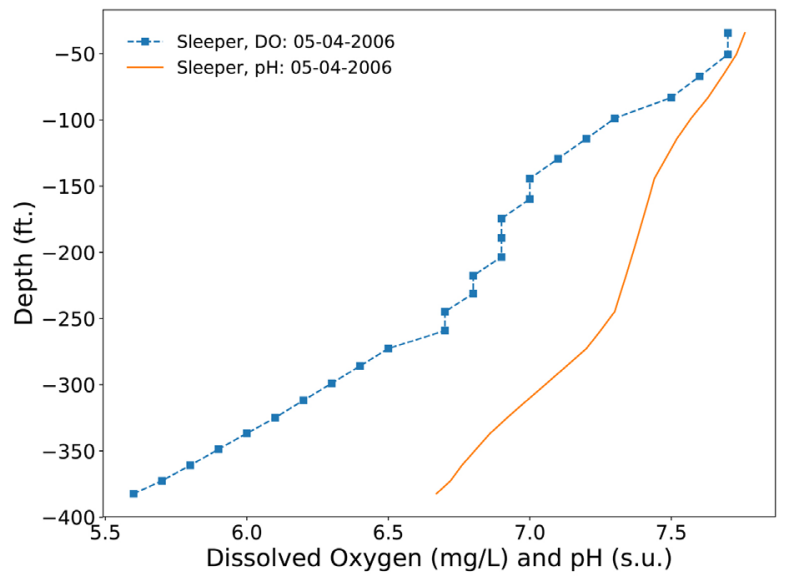

(d)

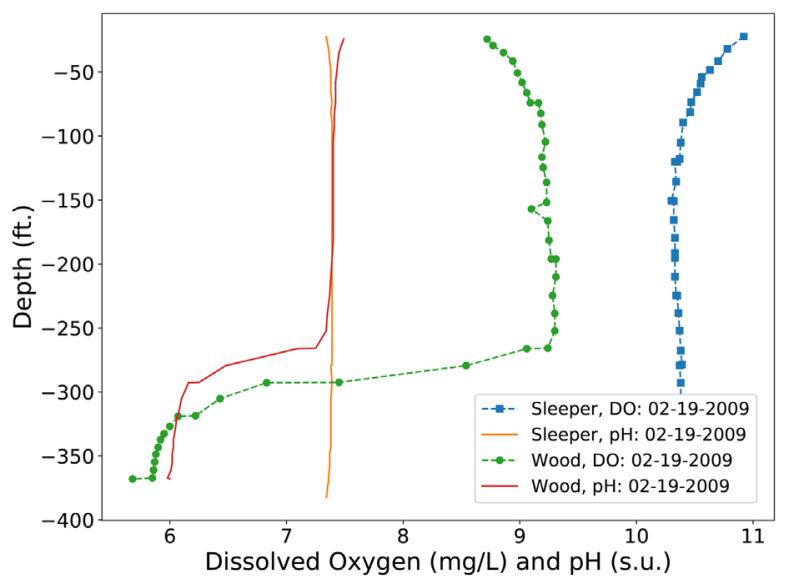

(f)

Figure 4. CTD profiles of the sleeper and wood pits during the periods: (a)-(e) 2005-2006, and (f) spring 2009.

while the lower portion of the lake may receive relatively little groundwater inflow due to lower hydraulic conductivity volcanic rocks (Dowling et al., 2004). The influent groundwater from the basal alluvial gravel aquifer is generally high in alkalinity, with $\mathrm{pH}$, total alkalinity concentrations, and total dissolved solids (TDS) respectively averaging approximately 8.1 standard units (s.u.), $186 \mathrm{mg} / \mathrm{L}$ 
as $\mathrm{CaCO}_{3}$, and $752 \mathrm{mg} / \mathrm{L}$ (WSP, 2016).

Although only a snapshot in time, this analysis suggests that the Sleeper pit lake may have variable limnologic behavior, with some periods characterized by holomixis (Figure 2) and others characterized by meromixis (Figure 4). It is also interesting to note that even though both major pits of the original Sleeper mine are occupied by one contiguous pit lake, the limnologic behavior of these pits is not always linked. Figure 4(f) illustrates this point where the Sleeper pit experienced full turnover in early spring 2009 while the Wood pit remained stratified. The cause for the decoupled limnologic behavior is not known conclusively but could be due to the morphology of the different pits. The Wood pit is approximately $115 \mathrm{~m}$ (380 ft.) deep at the point where depth-profiling is com-

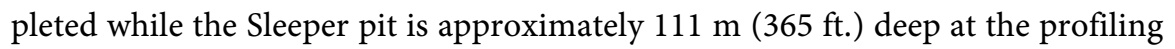
location. The larger surface area of the Sleeper pit when compared to the Wood pit may also lead to greater wind stress in the former pit. The slightly lesser depth and greater surface area may cause hydrodynamic instability in the Sleeper pit when compared to the Wood pit.

\subsection{Solute Generation in the Hypolimnion}

The rate of subaqueous pyrite oxidation (by both $\mathrm{O}_{2}$ and $\mathrm{Fe}^{\mathrm{III}}$ ) was calculated according to Equations (1) and (2). The relatively elevated Eh values observed in August 2018 and used in calculations $(200-230 \mathrm{mV})$ result in negligible calculated rates of pyrite oxidation by $\mathrm{Fe}^{\mathrm{III}}$ of approximately $10^{-11} \mathrm{~mol} / \mathrm{m}^{2} \cdot \mathrm{sec}$. As described previously, this calculation suffers from poor availability of Eh measurements and should therefore be interpreted cautiously. However, the low rate of Fe-driven pyrite oxidation is conceptually consistent with the overall low Fe concentrations in the pit lake during all periods. Of the $204 \mathrm{Fe}$ measurements available, 171 were below the typical detection limit of $0.01 \mathrm{mg} / \mathrm{L}$ (including both stratified and unstratified time periods). These low dissolved Fe concentrations are in agreement conceptually with the net reaction proposed in Equation (9), wherein pyrite is oxidized but no dissolved Fe is produced due to immediate formation of Fe-oxyhydroxide.

Calculated pyrite oxidation rates by $\mathrm{O}_{2}$ are orders of magnitude greater than that by $\mathrm{Fe}^{\mathrm{III}}$. These rates vary seasonally and with depth (Figure 5), wherein greater oxidation rates are calculated for the epilimnion than the hypolimnion. However, only the hypolimnion rates are likely applicable for pyrite oxidation as the saturated potentially-acid generating (PAG) backfill placed in the bottom of the pit is not in contact with the epilimnion waters except immediately following turnover events when the lake homogenizes. The absolute rates shown in Figure 5 are somewhat difficult to interpret without context. For comparison, Gammons (2009) calculated a range of rates for the Berkeley pit lake, Montana, and estimated a range of approximately $10^{-8.5}$ to $10^{-6} \mathrm{~mol} / \mathrm{m}^{2} \cdot \mathrm{sec}$, depending on $\mathrm{pH}$ conditions and Fe concentrations.

Basic mass-balance calculations can be completed using the central tendency 


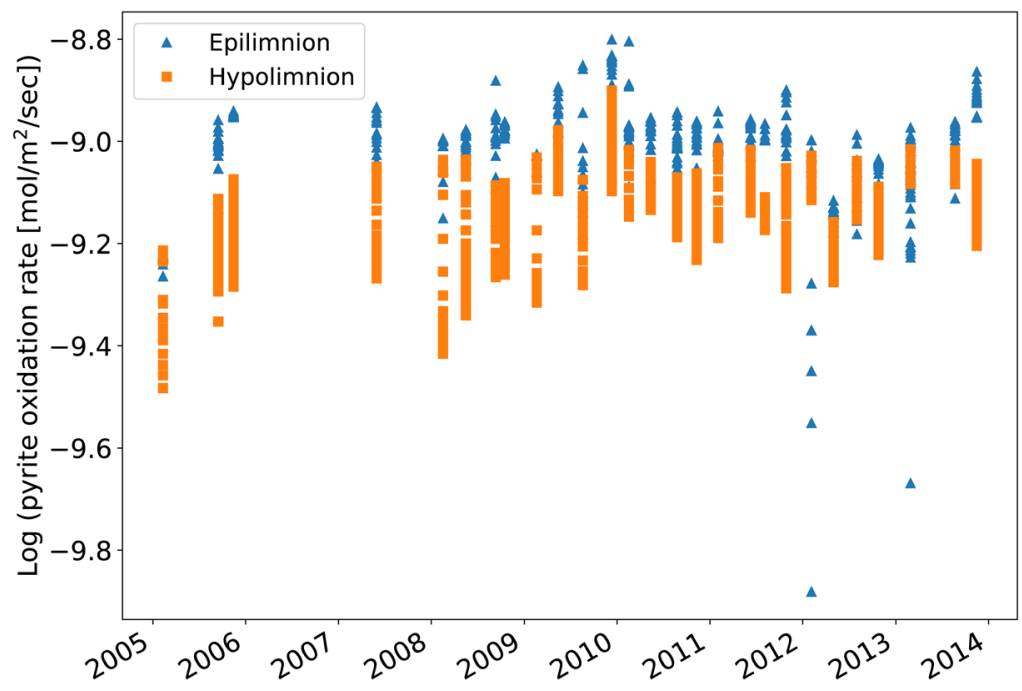

Figure 5. Pyrite oxidation rates by $\mathrm{O}_{2}$ in the epilimnion and hypolimnion. The rate of oxidation by $\mathrm{Fe}^{\mathrm{III}}$ is negligible on this scale.

of the pyrite oxidation rate $\left(10^{-9} \mathrm{~mol} / \mathrm{m}^{2} \cdot \mathrm{sec}\right)$ and some assumptions regarding the surface area of backfill participating in oxidation. These assumptions include: the mass of saturated PAG backfill (calculated using the known volume of backfill; $6.39 \times 10^{9} \mathrm{~m}^{3}$ according to WSP (2016), and a density of $2200 \mathrm{~kg} / \mathrm{m}^{3}$ assuming disaggregation of volcanic rock), the proportion of pyrite in the backfill (conservatively assumed as $1 \%$ ), and the specific surface area (SSA) of backfill. No SSA measurements of the backfill are available, but a wide range has been reported in the literature (e.g., McLemore et al., 2009), an assumption of 0.5 $\mathrm{m}^{2} / \mathrm{kg}$ is likely a low value but provides a conservative lower bound to the calculations.

The result of these calculations (combined with the stoichiometry of the pyrite oxidation reaction in Equation (5)) is that $8000 \mathrm{mg} / \mathrm{L}$ of sulfate would be liberated into the hypolimnion each year. This result is clearly at odds with observations of sulfate concentrations hovering at approximately $1400 \mathrm{mg} / \mathrm{L}$ (Figure 2(f)). These calculations therefore overestimate pyrite oxidation, which could be explained by a variety of factors. For example, the pyrite-oxidation rate calculations may not be applicable because of the limited number of Eh measurements; the SSA value used may not be applicable; the pyrite may be encapsulated in silica (reducing the surface area; which is consistent with the mineralization at the deposit); or finally there could be inaccuracy in the total surface area of saturated backfill participating in the reaction. This latter factor is the most likely cause of the apparent inconsistency of the calculation. During the closure of the mine, local alluvium which contained both Fe-oxides and carbonate material was placed on top of the PAG backfill. This alluvial material likely provides neutralizing agents to buffer any produced acidity, and generally limits the interaction of pit-lake waters with the backfill. Therefore only a small proportion of the backfill is likely taking part in any subaqueous sulfide oxidation. 
One possible series of reactions responsible for the generation of $\mathrm{Mn}$, without appreciable Fe, is described in Equations (4)-(9). One way to evaluate the applicability of this series of reactions is by quantifying changes in the molar ratios of all constituents over time. Most notably the net reaction produces 8 moles of sulfate and 16 moles of $\mathrm{H}^{+}$for each mole of $\mathrm{Mn}$. However, the calculated acidity changes over time (Figure 3 ) and variability in $\mathrm{pH}$ (Figure 2(b)) are much less than this reaction would predict. Also, quantification of the molar ratios over time of these constituents show that these ratios are not maintained in the actual pit lake. Taken together these results show that the exact balanced reaction in Equation (9) is not occurring in the saturated backfill in the Sleeper pit lake, or other additional processes are also involved. The ratios of constituents to one another would be different if a different series of reactions were utilized, and it is important to note that $\mathrm{Mn}$ release through reductive dissolution is not dependent on pyrite oxidation (Equation (4)), which may explain the observations. Further evaluation of the detailed reactions and processes involved may require additional data collection, possibly including evaluation of sediment cores and pore water analyses.

\subsection{Monimolimnion Formation and Chemical Diffusion}

The observed CTD profiles of the Sleeper pit lake indicate that a monimolimnion may form in some years, although the stratification is sometimes destabilized promoting full mixing of the pit lake. It is important to note that the monimolimnion may not have been subject to water-quality monitoring in the past. The deepest water-quality sample collected from the pit lake to date is approximately $100 \mathrm{~m}$ ( $330 \mathrm{ft}$.) below water surface, compared to the current maximum lake depths of approximately $115 \mathrm{~m}$ (380 ft.) and $111 \mathrm{~m}$ (365 ft.) in the Wood and Sleeper pits respectively. The monimolimnion (when it exists) may be present only at depths of $107 \mathrm{~m}$ (350 ft.) and deeper (see Figure 4), meaning that the chemical composition of monimolimnion waters would not be sampled during routine water-quality monitoring. It is possible that diffusion from the monimolimnion (or sediment pore waters) could be causing the seasonal fluctuations evident in the metal concentrations and $\mathrm{pH}$ as suggested in conceptual model C in this study. Fick's law (Equation (10)) was used to evaluate this potential for diffusion from the monimolimnion or sediment pore waters.

Diffusion calculations could be completed for dissolved constituents (e.g., Fe, $\mathrm{Mn}$, etc.), however with only three available water-quality sampling depths, these calculations may not be indicative of actual behavior due to the coarse resolution with depth of the observations. Therefore, diffusion calculations were only completed for $\mathrm{H}^{+}$because this parameter has been measured with a fine depth resolution (i.e., measurements every $1 \mathrm{~m}[\sim 3 \mathrm{ft}$.$] ) on a number of occa-$ sions through CTD profiling. Diffusion calculations could be completed for all events with available CTD profiles, however only one is included here (September 15th 2005 from the Sleeper pit) for the sake of simplicity. This is the same 
date as the profile shown in Figure 4(a). The calculations are defined such that the $\mathrm{z}$ dimension is positive with increasing depth in the pit lake. Therefore a negative flux indicates upward diffusion in the water column, and vice versa.

The results of the calculations (Figure 6) illustrate an upward diffusive flux of $\mathrm{H}^{+}$(essentially the upward migration of lower $\mathrm{pH}$ conditions) from the sediment-water interface in September of 2005, when the lake is believed to have been meromictic. This upward flux of $\mathrm{H}^{+}$continues nearly to the surface of the lake. It is worthwhile to note that this calculation mirrors the observed gradient in $\mathrm{pH}$, and therefore the calculation is not independent of those observations. The calculation merely quantifies the mass-transport of the variable $\mathrm{pH}$ zones. Because the calculations are driven by observations, diffusion calculated using monitoring data from other dates would arrive at different results. Also, the surface area of the bottom of the lake (estimated as $\sim 117,000 \mathrm{~m}^{2}$ ) and the diffusion coefficient are sources of potential error in this calculation. While the diffusion results illustrated in Figure 6 may not be indicative of long-term behavior, the main result of the calculations remains valid. This conclusion is that a diffusive flux of $\mathrm{H}^{+}$was emanating from the lower lake or the sediment-water interface on the date shown in Figure 6.

Although these results indicate that diffusion of some chemical species could be controlling dissolved concentrations in the lake, it is interesting to note that the process of double diffusion is not observed in the Sleeper pit lake. Double diffusion is a physical process involving variable diffusive fluxes of heat and dissolved solutes that has been attributed with various water quality changes observed in some meromictic pit lakes (Boehrer et al., 2009; von Rohden et al., 2010). This process is generally indicated by a stair-stepped appearance in the conductivity and temperature profiles of the lake, which is not typically observed

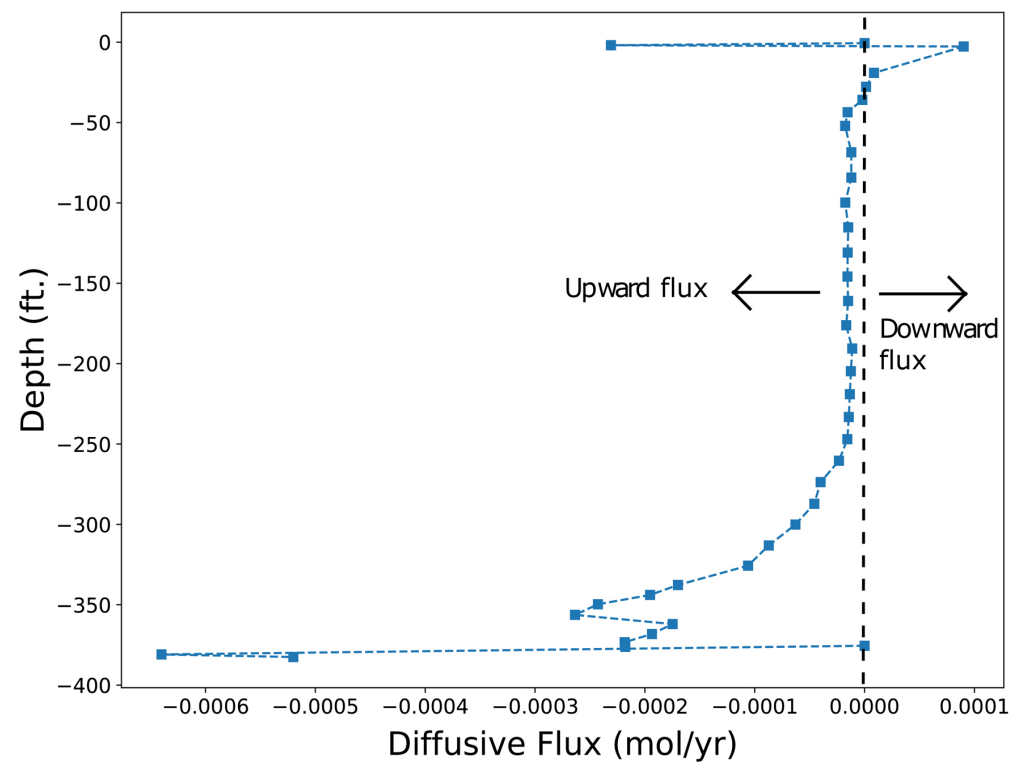

Figure 6. Results of Fickian $\mathrm{H}^{+}$diffusion calculations for September 15th 2005, the dotted vertical line denotes a diffusive flux of zero. 
in Sleeper. The Sleeper pit lake may lack this process due to the variable limnologic behavior over time, where the lake apparently is meromictic in some years and holomictic in others. Double diffusion may require more long-term stratification to develop.

\section{Conclusion}

The Sleeper pit lake is somewhat unique among Nevada pit lakes in that it is apparently meromictic in some time periods (fall 2005 to fall 2006 for example), while it undergoes full mixing (holomixis) in other periods. The cause for the variable behavior is not known but warrants further investigation.

This analysis has clearly demonstrated subaqueous geochemical changes in the Sleeper pit lake, despite not providing a complete understanding of the mechanisms leading to these observed changes. Several processes were evaluated including subaqueous pyrite oxidation, redox reactions, and diffusion of $\mathrm{H}^{+}$ions from the monimolimnion. Although none of these phenomena can be implicated with certainty, the observed water-quality trends are likely partially the result of a combination of these processes. Several important lines of additional characterization could be completed to provide insight on these processes including sampling of backfill pore waters and the sediment column, and sampling water quality near the bottom of the lake to evaluate monimolimnion chemistry (when applicable). Regardless of the lack of concrete evidence as to mechanistic processes, these findings have important implications for ultimate closure planning in pit lakes:

1) If necessary, sulfide material may be backfilled into a pit that will form a lake, but precautions need to be taken to minimize the oxidation that can occur prior to hydrologic stabilization of the lake. Also, this closure method is likely only applicable under certain geochemical and physical conditions (i.e., in deep stratified pit lakes with substantial influent alkalinity in groundwater and low $\mathrm{Fe}$ concentrations to minimize subaqueous pyrite oxidation by $\mathrm{Fe}^{\mathrm{III}}$ ).

2) Assumptions regarding annual turnover (i.e., that pit lakes will be holomictic in all years) may not be well-founded. The modeling and management strategies for meromictic lakes may be different than for holomictic lakes (e.g., Schultz et al., 2016). The possibility of long-term stratification, and the impact of this process on mine closure, should also be assessed.

3) Subaqueous generation of solutes is evident in the Sleeper pit lake (e.g., seasonal changes in Figure 2), although this does not change the current management strategy for the lake due to site-specific factors including high-alkalinity groundwater inflow and the large lake volume. However, in smaller lakes with less volume for dilution or without good-quality water sources, predictive modeling should evaluate the impact that long-term generation of solutes would have on water quality. If these processes are ignored in modeling and permitting studies, proponents risk underestimating the concentrations of important solutes (e.g., sulfate and metals) in future lakes, which may increase the time and cost of 
ultimate closure actions.

\section{Acknowledgements}

The original concept for this study was derived from a session at the annual conference of the Society of Mining, Metallurgy, and Exploration, and the authors appreciate the work of Jerry Vandenberg and Devin Castendyk in establishing the session at SME. The authors appreciate the help of Nancy Wolverson and Paramount Gold Inc., who allowed this work to be pursued for presentation at the SME conference. Two anonymous reviewers from the journal provided helpful comments.

\section{Conflicts of Interest}

The authors declare no conflicts of interest regarding the publication of this paper.

\section{Disclaimer}

The work described herein is the opinion of the authors only, and does not represent the opinion of the government of the State of Nevada or any private companies.

\section{References}

Appelo, C. A. J., \& Postma, D. (2005). Geochemistry, Groundwater and Pollution (p. 649). The Netherlands: A.A. Balkema Publishers.

https://doi.org/10.1201/9781439833544

Aqion (2018). Table of Diffusion Coefficients. http://www.aqion.de/site/194

Balistrieri, L. S., Tempel, R. N., Stillings, L. L., \& Shevenell, L. A. (2006). Modeling Spatial and Temporal Variations in Temperature and Salinity during Stratification and Overturn in Dexter Pit Lake, Tuscarora, Nevada, USA. Applied Geochemistry, 21, 1184-1203. https://doi.org/10.1016/j.apgeochem.2006.03.013

Boehrer, B., Dietz, S., von Rohden, C., Kiwel, U., Jöhnk, K. D., Naujoks, S., Ilmberger, J., \& Lessmann, D. (2009). Double-Diffusive Deep Water Circulation in an Iron-Meromictic Lake. Geochemistry, Geophysics, Geosystems, 10, Q06006.

https://doi.org/10.1029/2009GC002389

Castendyk, D. N. (2009). Predictive Modeling of the Physical Limnology of Future Pit Lakes. In D. N. Castendyk, \& L. E. Eary (Eds.), Mine Pit Lakes: Characteristics, Predictive Modeling, and Sustainability (pp. 101-114). Littleton, CO: Society of Mining, Metallurgy, and Exploration.

Castendyk, D. N., \& Eary, L. E. (2009). Mine Pit Lakes: Characteristics, Predictive Modeling, and Sustainability (p. 304). Littleton, CO: Society of Mining, Metallurgy, and Exploration.

Castendyk, D. N., Eary, L. E., \& Balistrieri, L. S. (2015). Modeling and Management of Pit Lake Water Chemistry 1: Theory. Applied Geochemistry, 57, 267-288.

https://doi.org/10.1016/j.apgeochem.2014.09.004

Dowling, J., Atkin, S., Beale, G., \& Alexander, G. (2004). Development of the Sleeper Pit Lake. Mine Water and the Environment, 23, 2-11. https://doi.org/10.1007/s10230-004-0038-y 
Eary, L. E., \& Castendyk, D. N. (2013). Hardrock Metal Mine Pit Lakes: Occurrence and Geochemical Characteristics, Chapter 3.2.2. In W. Geller, M. Schultze, B. Kleinmann, \& C. Wolkersdorfer (Eds.), Acidic Pit Lakes: The Legacy of Coal and Metal Surface Mines (p. 526). Berlin: Springer.

Gammons, C. H. (2009). Subaqueous Oxidation of Pyrite in Pit Lakes. In D. Castendyk, N., \& L. E. Eary (Eds.), Mine Pit Lakes: Characteristics, Predictive Modeling, and Sustainability (pp. 137-145). Littleton, Colorado: Society of Mining, Metallurgy, and Exploration.

Jewell, P. W. (2009). Stratification Control of Pit Mine Lakes. Mining Engineering, 61, 40-45.

Kirby, C. S., \& Cravotta III, C. A. (2005). Net Alkalinity and Net Acidity 1: Theoretical Considerations. Applied Geochemistry, 20, 1920-1940.

https://doi.org/10.1016/j.apgeochem.2005.07.002

Kumar, R. N., McCullough, C. D., \& Lund, M. A. (2009). Water Resources in Australian Mine Pit Lakes. Mining Technology, 118, 205-212.

https://doi.org/10.1179/174328610X12682159815028

Martin, A. J., \& Pedersen, T. F. (2002) Seasonal and Interannual Mobility of Arsenic in a Lake Impacted by Metal Mining. Environmental Science and Technology, 36, 1516-1523. https://doi.org/10.1021/es0108537

McLemore, V. T., Fakhimi, A., van Zyl, D., Ayakwah, G. F., Anim, K., Boakye, K., Ennin, F., Felli, P., Fredlund, D., Gutierrez, L. A. F., Nunoo, S., Tachie-Menson, S., \& Viterbo, V. C. (2009). Questa Rock Pile Weathering Stability Project. Literature Review of Other Rock Piles: Characterization, Weathering, and Stability. New Mexico Bureau of Geology and Mineral Resources. Open-File Report OF-517, June.

Nash, J. T., Utterback, W. C., \& Trudel, W. S. (1995). Geology and Geochemistry of Tertiary Volcanic Host Rocks, Sleeper Gold-Silver Deposit (p. 69). Humboldt County, NV: U.S. Geological Survey Bulletin 2090.

Ramteke, S., Verma, V., Chakradhari, S., Sahu, P. K., Sahu, B. L., Rajhans, K. P., Yadav, A., \& Patel, K. S. (2016). Pit Lake Water Quality of Central India. Journal of Geographic Information System, 8, 28-39. https://doi.org/10.4236/jgis.2016.81003

Sánchez-España, J., López Pamo, E., Pastor, E. S., \& Ercilla, M. D. (2008). The Acidic Mine Pit Lakes of the Iberian Pyrite Belt: An Approach to Their Physical Limnology and Hydrogeochemistry. Applied Geochemistry, 23, 1260-1287.

https://doi.org/10.1016/j.apgeochem.2007.12.036

Schultze, M., \& Boehrer, B. (2009). Induced Meromixis. In D. N. Castendyk, \& L. E. Eary (Eds.), Mine Pit Lakes: Characteristics, Predictive Modeling, and Sustainability (pp. 239-248, 304). Littleton, CO: Society of Mining, Metallurgy, and Exploration.

Schultze, M., Castendyk, D., Wendt-Potthoff, K., Sánchez-España, J., \& Boehrer, B. (2016). On the Relevance of Meromixis in Pit Lakes-An Update. In Proceedings of the International Mine Water Association (pp. 227-235). Leipzig: International Mine Water Association.

Tucci, N. J., \& Gammons, C. H. (2015). Influence of Copper Recovery on the Water Quality of the Acidic Berkeley Pit Lake, Montana, U.S.A. Environmental Science and Technology, 49, 4081-4088. https://doi.org/10.1021/es504916n

von Rohden, C., Boehrer, B., \& Ilmberger, J. (2010). Evidence for Double Diffusion in Temperate Meromictic Lakes. Hydrology and Earth System Sciences, 14, 667-674. https://doi.org/10.5194/hess-14-667-2010

WSP (2016) 2016 Sleeper Pit Lake Model Update (p. 40). Unpublished Consulting Report Prepared for Paramount Gold by WSP Parsons Brinckerhoff. 